\title{
Mixed Training: A New Perspective of Post-Service Training for Teachers
}

\author{
Xuntao Yue, Ziling Liu \\ Chengdu Normal University, Chengdu, China \\ Email: hnlyj1999@126.com
}

How to cite this paper: Yue, X.T. and Liu, Z.L. (2019) Mixed Training: A New Perspective of Post-Service Training for Teachers. Open Journal of Social Sciences, 7, 128-135.

https://doi.org/10.4236/jss.2019.76010

Received: April 30, 2019

Accepted: June 16, 2019

Published: June 19, 2019

Copyright () 2019 by author(s) and Scientific Research Publishing Inc. This work is licensed under the Creative Commons Attribution International License (CC BY 4.0).

http://creativecommons.org/licenses/by/4.0/

\begin{abstract}
The effectiveness of teacher training has been criticized. To change this situation, it is advisable to use mixed training instead of single training mode. Mixed training combines the advantages of various training modes, expands the learning space of teachers, constructs a system of mutual support among teachers, forms a three-dimensional model of teacher training and normalization of teacher training, and effectively promotes the professional development of teachers.
\end{abstract}

\section{Keywords}

Teachers Training, Mixed Training Model, Enlightenment

\section{Introduction}

Americans once mocked teacher's after-service training like this: "Teacher training means that teachers use boring lectures to tell teachers how to avoid boring lectures in class" [1]. This kind of state is also common in teacher training in our country, which is manifested in the fact that experts, in face to face lectures, concentrate on theories, which sound "noble", but are divorced from the actual situation of teachers' education and teaching in primary and secondary schools, and are not grounded.

The distance network training overcomes the limitation of time and space, but it is transmitted by one-way information indoctrination. Without classroom effect construction and positive teaching interaction, it is relatively boring, and it cannot be effectively monitored and directed; the school-based training links the real working environment, but lacks theoretical guidance and promotion, acting blindly, etc. These phenomena not only greatly reduce the training effect, but also affect teachers' recognition of training activities and enthusiasm for partici- 
pation. A survey of 162 teachers in primary and secondary schools (Specify the place the survey is carried out) shows that $86 \%$ of the respondents believe that the reason why teachers are unwilling to participate in training is that the training is not effective or targeted [2]. There are various factors that lead to inefficiency of teacher training activities. In terms of teacher training methods, one of the important factors is that a single training mode is not likely to meet the diversified needs of teachers. Therefore, the author believes that the mixed training of teachers is a new perspective of teachers' post-service training.

\section{Connotation of Mixed Training}

In the late 1990s, with the increasing number of trainees and the expanding geographical distribution of trainees (Reformulate), the managers training of IBM's Basic Blue in the United States began to improve the face-to-face training form. The online training combined network video and online tutor guidance was adopted, which become very popular with the participants as soon as it appears and also received a high return on investment. Since then, with the further innovation and rapid development of network technology, network training has been rapidly promoted. In 2002, American teachers trained teachers through the Education Information Technology Support System and online training of teachers. This method has effectively promoted the improvement of the quality of American teachers. "Survey shows that online training has become the mainstream of teacher training in the United States, reaching tens of billions of dollars per year. Online training has become the mainstream development direction of teacher training" [3]. "More than 50 per cent of Canadian teachers use the Internet for training, and the number of teachers trained through online resources is increasing year by year" [3]. In China, distance training has also received more and more attention and attention from training institutions, and has now been widely promoted and applied.

At home and abroad, when online training provides great convenience for teacher training, some people once thought that online training will completely replace offline training, but the fact is that online training not only does not replace offline training, but encounters the danger of being marginalized. The reason is that network training has its own inevitable shortcomings, such as lack of emotional communication between trainees, insufficient face-to-face interaction and group discussion, insufficient participation of trainees, inability to understand the needs of trainees, training feelings and psychological state, trainees cannot experience the atmosphere of collective learning provided by training institutions, so that trainees' learning depth and psychological state are inadequate, which results in the training effect not being guaranteed. Looking back on the traditional training methods, regardless of the specific working conditions of the participants, the participants in different regions are concentrated in a specific location during a specific period of time to solve a specific problem. Such training methods and contents cannot effectively meet the individual differences 
of teachers and effectively solve many problems in education and teaching. They have not understood and studied the psychological needs and feelings of participants, and the impact of training has also been short-lived, resulting in "training resources cannot be efficiently used and shared, the training process is relatively closed, the extended learning difficulties of trainees after training are encountered, and so on" [4]. Because of the different training methods, the quality and effect of training are quite different. All kinds of drawbacks of online and offline training urge all kinds of teacher training institutions to improve and combine the traditional training mode and remote network training in order to improve the training effect. Thus forming a three-dimensional model of teacher training mixed training, through investigating and analyzing the needs of trainees. The training content and training media resources are selected according to the characteristics of training projects and the actual needs of participating teachers, various training methods are integrated, their respective advantages are taken, and the training effect is optimized.

Mixed training was first considered to be a combination of traditional classroom instruction and emerging network-based instruction and learning [5]. According to Professor He Kekang, "Mixed training is to combine the advantages of traditional learning with those of network learning. It should not only play the leading role of teacher guidance and inspiration, but also fully reflect the initiative, enthusiasm and creativity of students as learning subjects" [6]. Some scholars believe that "mixed training" refers to a kind of training mode that applies the principle of mixed learning to the field of teachers' continuing education and training, integrates face-to-face training and network training, and effectively combines school-based research and visiting exchanges with teachers, and organically optimizes the combination of various training elements [7]. This way is not only the mixture of various training methods and training resources, but also the organic integration of training concepts and self-learning concepts. Other scholars have further expanded the connotation of mixed training, believing that mixed training is a new training mode constructed by reflecting on traditional teacher training. It can be a combination of online training and offline training, or a choice of more than two forms of training among replacement training, centralized training, school-based training, distance training, network training, on-site practice, mobile learning and other training modes, or the integration of theoretical training and focused classroom practice [8]. It expands the space for teachers to learn.

\section{Characteristics of Mixed Training}

Mixed training is not only a mixture, but also a kind of integration. Its core essence is how to "integrate", that is, how to "mix". The main manifestation of such integration: The first is the integration of training time. Mixed training is no longer a one-time short-term training, but a regular cyclical training. The second is the integration of training venues. Mixed training takes place not only 
in training institutions (such as colleges and universities), but also in schools where participants work, specific cyberspace communities(such as teacher workshops), and teachers own homes and so on, creating a training place that combines theoretical guidance with practical education and teaching problem solving. The third is the integration of training content, which is no longer based on a single type of training, but rather a multi-dimensional training on teaching, teaching and research, training and other training content (such as teachers' ethics, mental health and legal system), moving the teacher from trainees to trainers and researchers The fourth is the integration of training institutions. Mixed training institutions are no longer just declared or implemented by one unit or one department, but collaboratively declared and implemented by multi-unit and muti-department such as universities, remote institutions, County (city) education administration departments, District (county) teacher professional development schools and high-quality primary and secondary schools; The fifth is the integration of guiding theory. The diversified theoretical bases of mixed training mainly include lifelong learning theory, mixed learning theory and adult learning theory. The sixth is the integration of training methods. Mixed training mainly uses the combination of online training and offline research, but also combination of other forms of training, to achieve the mutual integration and mutual penetration of a variety of training methods, and thus, "to achieve diversification, localization, whole process, full staff and effectiveness of teacher training." Therefore, teachers' mixed training embodies the following characteristics:

\subsection{Temporal Spirit}

Teachers' mixed training is a reform of the traditional training mode in the field of education and a reflection on the training under the purely technical environment after the low tide of distance training. It is a new concept emerging in the educational circles. Although it is a new theory of teacher training, it has become a new perspective of teacher training. At present, many educators and scholars have deeply explored and actively applied it to teacher training practice. Therefore, mixed training has obvious characteristics of the times. With the continuous innovation of network science and technology, the development of modern education technology, and the continuous deepening of teacher training, mixed training will also continue to develop and improve.

\subsection{Cooperativity}

Teachers' mixed training is a declaration and implementation system mainly composed of municipal (district) educational administrative departments and training institutions (universities, distance training institutions). It also includes the joint participation of municipal educational research institutes, audio-visual education centers, teachers' professional development schools (counties, districts), high-quality primary and secondary schools and kindergartens, and the 
lack of any one unit will affect the effectiveness of mixed teacher training. Firstly, the training needs of teachers in different regions are scientifically diagnosed. Then, universities take the lead, distance training institutions, County (district) education bureaus and participating teachers work together to formulate training plans and programs. Through the collaborative process, a peer-to-peer support system for teacher training is established, and then it is implemented step by step across the year, classifying, dividing and stratifying. Finally, a teacher learning community is formed to promote the common growth of teachers.

\subsection{Practicality}

The starting point of mixed training practice comes from enterprise training, which reduces the cost of training to a certain extent and increases the profits of enterprises. In the field of teacher training, in recent years, many experts and scholars have paid more and more attention to and conducted in-depth research on mixed teacher training, and various forms of mixed teacher training practice have emerged in many regions of the country. Most of the scholars who study mixed training are teachers' training staff. Most of their research results come from the experience summary and reflection of teachers' mixed training practice. At the same time, they also puts forward a series of theoretical and strategic research, which in turn further guide the practice of mixed training, that is, research in practice and practice in research, highlighting the practicality of teacher mixed training.

\subsection{Normalization}

The important goal of teachers' mixed training is to enhance the effect of teachers' training, to improve the satisfaction of participants in training, and to improve the comprehensive quality of teachers themselves, moving them from trainees to trainers and researchers, and making them able to not only train other teachers in school and but also study the school's educational and teaching practice, and "eventually, establish a support service system for teachers' professional development, form a normal operating mechanism of teachers' autonomous learning community, build a normal teacher training institution, and promote the normalization of teacher training." From the normalization of teacher training to the normalization of teacher professional development, teachers' normal learning is promoted, and a large number of excellent teachers are trained, so as to improve the overall level of teachers.

\subsection{Development}

Teachers' mixed training is a growing new thing, which needs to be continuously studied and developed. Its development is embodied in two main aspects: First, its theory should be constantly developed, enriched and perfected, the mixed training mode and method will be more and more diversified, the content of mixed training will be more and more extensive, and the quality resources will 
be constantly generated. Second, the practice of mixed training will continue to deepen, and various types of training will participate in it, constantly verify its theory, and promote the implementation of mixed training.

\section{The Enlightenment of Mixed Training on Teacher Training}

Mixed training has important enlightenment to the current teacher training, which is embodied in the following aspects:

1) Integrating the advantages of various training methods, it promotes the effective development of teacher training and forms a new normal of teacher training.

Mixed training, which integrates various training methods, has become a new attempt to reform teacher training mode. Mixed training actively mobilizes the main role of trainees while giving full play to the dominant role of trainers in single training. It also pays attention to the space-time convenience of distance training, and properly integrates the advantages of various training methods, as follows:

a) Pay attention to the study, exchange and discussion of centralized training, the interaction and guidance under distance training, and focus on the practical problems of education and teaching.

Mixed training focuses on theoretical guidance, learning and communication through traditional training forms. It also focuses on educational issues through on-site teaching practice or on-the-job training. It also uses distance training to share educational resources such as high-quality videos and communicates with leading teachers or theoretical instructors at any time and anywhere through teacher workshops. Teachers participating in training can choose training and learning contents and methods according to their actual needs of education and teaching, interact with training experts, diagnose classroom teaching, watch and polish classes, share teaching results, achieve synchronous or asynchronous interaction among educational experts, front-line famous teachers and participating teachers, as well as between participating teachers and educational and teaching resources, so that participating teachers can learn through training, learn something useful, be willing to summarize, be good at upgrading, and let mixed training move from effective training to accurate training.

b) It emphasizes the close connection between training content and teaching practice, and also emphasizes the combination of the training participants' existing teaching experience, knowledge and new learning educational teaching theory or curriculum reform concept.

Mixed training lies in the precise implementation of organic integration, and constantly explores the logic of its development. Teacher training has its own development law. Starting from the objective reality, we should master the operation law of teacher training and follow the process of training project planning, project empirical investigation, training program formulation, training program 
implementation, practice research and guidance, remote tracking service, evaluation and assessment, summary and promotion, innovation and promotion. At the same time, the construction of mixed training resources originates from the actual needs of teachers' education and teaching. These resources are based on the reality of school education, teachers' own professional development, curriculum development and reform, starting from the problems of education and teaching, layering and classifying training contents, and providing strong support services for teachers' development. Let teacher training return to the realistic situation of the development of education and teaching, to the practical problems of teachers' professional development, to the practical problems of teachers' education and teaching, to the logic of teachers' training self-development, to effectively solve the practical puzzles in the process of teachers' professional development, and to realize teachers' professional development.

2) Forming the model of peer-to-peer assistance in teacher training, constructing the system of peer-to-peer support, and forming the three-dimensional model of teacher professional development.

There are two main types of peer assistance in teachers' mixed training: top-down peer assistance model and bottom-up peer assistance model. The top-down model is mainly established by the administrative way between training institutions (such as universities, distance training institutions) and education administration (such as the urban education bureau) in the mixed training. The main form of organization is "expert-trainee teacher mutual assistance". This kind of organization is mainly "other organization" model. That is to say, the educational administrative departments and training institutions construct a network virtual community and teacher workshops platform for the trainees through mixed training forms, and then organize training experts (university discipline experts, district and county teachers, backbone disciplines, famous teachers, etc.) to guide the trainees to form a learning community, participate in teachers' off-line on-site teaching and classroom observation, and conduct teaching points. Only when there are problems can we organize concentrated theoretical study or online communication and discussion, condense the research topics, and realize the creation, expression and sharing of practical knowledge of participating teachers.

The bottom-up peer-to-peer model mainly involves the return of teachers who have participated in mixed training to their work units. Based on School-based research, "on the basis of voluntary formation, training organizers mainly play the role of encouragement and support, highlighting the dominant position of teachers, equal status of participants, democracy in dialogue, honesty and openness in communication." Mainly "peer assistance", the organizational form is from "other organization" to "self-organization", and the combination of "self-organization" and "other organization" is implemented to form a teacher learning community. That is to say, the head of the subject teaching and research group (the head of the school teaching and research group, the backbone teachers, etc.) organizes the activities of school-based research and observation and 
grinding, and publishes the school-based research plan. Designate teachers and students to participate in teaching design, organize off-line teaching and classroom observation, organize online discussions and exchanges, condense research topics, publish research summaries, and realize the creation, expression and sharing of teachers' practical knowledge in schools.

In a word, the top-down "expert-teacher mutual assistance" is mainly to ensure and support the training institutions and educational administrative departments in the system, and to guide, supervise and coordinate learning. Bottom-up "peer assistance" is to share educational and teaching resources among schools, schools and regions. It can be seen that peer-to-peer assistance of teachers runs through all aspects of teacher centralized training, distance training, school-based research, sending education to the countryside, and teacher workshops. Only mixed training can build a platform of peer-to-peer support for teachers' professional development, form a three-dimensional model of teacher training, promote the normalization of teachers' learning, and thus improve the overall level of teachers.

\section{Conflicts of Interest}

The authors declare no conflicts of interest regarding the publication of this paper.

\section{References}

[1] Wu, W.D. (2008) Experiential Training: A New Perspective of Teacher Training. Research on Educational Development, No. 15, 56.

[2] Liu, Y.J. (2014) Replacement of Off-Job Research: A New Perspective of Rural Teachers' Post-Service Training. Journal of Chengdu Normal University, No. 9, 28.

[3] Yang, W.M. (2007) Research on the Current Situation and Development of Online Learning. Northwest Normal University, Lanzhou, 33-35.

[4] Ruan, L.F., Zhang, S.J. and Zhou, D.N. (2012) Construction of Network-Face-To-Face Integrated Training Mode. Continuing Education, No. 6, 8.

[5] Shi, Y.F. (2015) Knowledge Conversion: An Effective Way to Mining the Maximum Effectiveness of Mixed Training. Primary and Secondary School Teacher Training, No. 4,31 .

[6] He, K.K. (2004) The New Development of Educational Technology Theory from the Perspective of Mixed Learning. Research on Audiovisual Education, No. 3, 1.

[7] Liu, L.N. (2014) Research and Practice of On-the-job Teachers' Mixed Training Model Based on the Principle of Mixed Learning. Journal of Beijing Institute of Education, No. 2, 11.

[8] Zhou, X.F. and Yang, F.Y. (2015) Practice of Mixed Training Integration for Rural Primary and Secondary School Teachers. Modern Vocational Education, No. 10, 106. 